\section{Retinoblastoma frontiers with intravenous, intra- arterial, periocular, and intravitreal chemotherapy}

Eye (2013) 27, 288; doi:10.1038/eye.2012.218; published online 19 October 2012

Correction to: Eye (2013) 27, 253-264; doi:10.1038/ eye.2012.175; published online 21 September 2012

Since the online publication of the above article, the authors have noted that the name of the fifth
CL Shields, EM Fulco, JD Arias, C Alarcon, M Pellegrini, P Rishi, S Kaliki, CG Bianciotto and JA Shields

author was incorrect. The correct details are given above.

The authors would like to apologise for this error. 